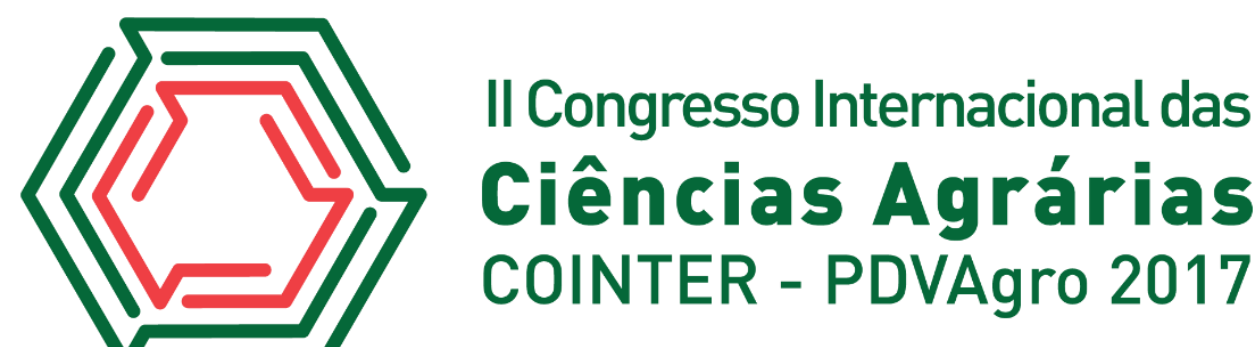

\section{AGREGAÇÃO E ESTOQUE DE CARBONO DEEM SOLOS CULTIVADOS COM CAFÉ (COFFEA ARABICA L) NO OESTE BAIANO}

\author{
Apresentação: Pôster \\ Laise de Souza Silva ${ }^{1}$; Paulino Joaquim Soares Neto Sol ${ }^{2}$, \\ Vandayse Abades Rosa ${ }^{3}$; Heliab Bomfim Nunes ${ }^{4}$; Joaquim Pedro Soares Neto ${ }^{5}$
}

\section{Introdução}

Atualmente, é evidente as grandes mudanças que vem acontecendo no mundo, em se tratando da poluição ambiental, que são ocasionados por fatores prejudiciais, os quais podem ser destacados, a utilização de combustíveis fósseis e substâncias provenientes do mesmo (gasolina, diesel), sendo assim, acarretando no crescimento do dióxido de carbono do ar, que é um dos gases que aumenta a força radiativa agravando e acelerando o aquecimento global.

Diferentemente dos países industrializados, no Brasil a maior parcela das emissões líquidas estimadas de $\mathrm{CO}_{2}$ é proveniente da mudança do uso da terra, em particular da conversão de florestas para uso agropecuário, que contribui com mais de dois terços das emissões totais de gases de efeito estufa (GEE) no país. Aproximadamente $75 \%$ do $\mathrm{CO}_{2}$ que o Brasil emite para a atmosfera são derivados de práticas agrícolas e do desmatamento e $25 \%$ são derivados da queima de combustíveis fósseis (CERRI et al., 2007).

O oeste da Bahia é a região do Estado com maior área agrícola, principalmente com culturas de grãos, portanto estudos que avalie a comportamento do carbono no nesses solos tornam-se fundamentais para conhecer a contribuição da agricultura na emissão de gases capazes de promover o "efeito estufa", portanto, objetivou-se com esse estudo, avaliar a influência do café com diferentes idades nas propriedades físicas do solo e estoques de carbono no solo.

\footnotetext{
${ }^{1}$ Graduanda em Engenharia Agronômica, Universidade do Estado da Bahia (UNEB), laisinha_02@hotmail.com ${ }^{2}$ Graduando em Engenharia Agronômica, Universidade do Estado da Bahia (UNEB) paulinoagro@ hotmail.com, ${ }^{3}$ Graduanda em Engenharia Agronômica, Universidade do Estado da Bahia (UNEB), deyseabades@ hotmail.com ${ }^{4}$ Mestre em microbiologia do solo, Universidade do Estado da Bahia (UNEB), heliabnunes@ hotmail.com ${ }_{5}^{5}$ Doutor em Geotecnia, Universidade do Estado da Bahia (UNEB), jpsneto@uneb.br
} 


\section{Fundamentação Teórica}

A cafeicultura, atualmente, ocupa uma área de 2,2 milhões de hectares plantados no Brasil, segundo os dados da Companhia Nacional do Abastecimento (CONAB, 2016), sendo que o Brasil é maior produtor e o maior exportador mundial de café, com mais de 40,3 milhões de sacas beneficiadas na safra 2015/16. Desse total, cerca de 81,1\% é de café Arábica e o restante de café Conilon.

As espécies lenhosas, como o cafeeiro, armazenam carbono na madeira e em outros tecidos até a morte e decomposição, fase em que o carbono da madeira poderá ser desprendido na forma de gás carbônico, monóxido de carbono, metano, ou poderá Ficar estocado no solo como compostos orgânicos (Cotta et al., 2008), nesse sentido monitorar esse comportamento do carbono como também a qualidade física dos solos cultivados com essa cultura se torna medida importante para avaliar se tal sistema funciona como deposito de carbono mitigando dessa forma o efeito estufa global.

\section{Metodologia}

\section{Caracterização da Área em Estudo}

O estudo foi realizado na fazenda Dom Laurindo que fica situada no município de Luis Eduardo Magalhães, na Região Oeste da Bahia. Foram selecionados talhões com plantio de café nas idades de três, e vinte anos além da área de cerrado nativo.

\section{Clima}

De acordo a classificação de Koppen o clima predominante da região é do tipo Aw, ou seja, tropical sub úmido com período chuvoso de outubro a abril e período seco de maio a setembro.

\section{Amostragens}

\section{Solo}

Foram abertos perfis em quatro pontos em talhões com idades de três, e vinte anos, além da área de cerrado nativo nas profundidades de $0-0,10 ; 0,10-0,20 ; 0,20-0,30$ e 0,30 - 0,40 nos quais foram coletadas amostras indeformadas com o auxilio de um trado e anel volumétrico para as análises de densidade e estabilidade de agregados. E amostras deformadas para do carbono orgânico total. As amostras foram devidamente identificadas e encaminhadas para o laboratório de Física dos Solos da Universidade do Estado da Bahia (UNEB), Campus IX. 


\section{Carbono orgânico total}

O carbono orgânico total, foi determinado por oxidação a quente com dicromato de potássio em meio sulfúrico (Embrapa, 2011) e o estoque de carbono em cada uma das camadas amostradas foi estimado a partir da expressão:

Est $\mathrm{C}=\mathrm{COT} * \mathrm{Ds} * \mathrm{e}$

Onde: EstC é o estoque de carbono em $\mathrm{Mg} \mathrm{ha}^{-1}$; COT indica o teor de carbono orgânico total em g/kg; Ds é a densidade do solo da camada estudada em $\mathrm{kg} . \mathrm{dm}^{-3}$ e "e" a espessura da camada em centímetros (ALMEIDA,2014).

\section{Estabilidade de Agregados em água}

A estabilidade dos agregados foi determinada em amostras destorroadas cuidadosamente com as mãos quebrando os agregados maiores em seus pontos de fragilidade natural e posteriormente secas ao ar. Após esse processo, as amostras foram passadas num conjunto de peneiras, os agregados retidos na peneira de 8-10 $\mathrm{mm}$ foram utilizados para serem processados. Retirou-se 4 amostras de 50g por cada profundidade, em seguida essas amostras foram colocadas na parte superior de um jogo de peneiras de malhas $2,00 \mathrm{~mm} ; 1,00 \mathrm{~mm} ; 0,50 \mathrm{~mm} ; 0,25 \mathrm{~mm}$ e 0,106 $\mathrm{mm}$. Estas foram umedecidas com um atomizador e aguardado 10 minutos. Em seguida as amostras foram imersas no tanque do aparelho de Yoder para oscilação vertical por 15 minutos. Os agregados retidos em cada peneira foram transferidos para cápsulas de alumínio e levadas a estufa de circulação forçada por 24 horas a $105^{\circ} \mathrm{C}$ e na sequencia foi pesada cada fração (SALTON, 2012).

\section{Resultados e Discussões}

Observa-se na Tabela 1, que nas camadas de 0-10 e 20-30 não teve diferença estatística entre as áreas estudadas, entretanto nas camadas de 10-20 e 30-40, os valores maiores de macroagregação foram encontrados no cerrado nativo, devido ao aporte de cobertura vegetal presente nessa área, ser o suficiente para proteger estabilidade de agregados em água deste solo. NETTO et al. em 2001 em seus estudos de influência do manejo sobre a estabilidade de agregados em solo de cerrado sob cafeicultura constatou que esse comportamento se deve à pressão exercida pela roda do trator nesta região do cafeeiro, promovendo quebra dos agregados maiores e incremento na proporção dos agregados de menor tamanho.

Tabela 1: Macroagregados em áreas cultivadas com café em diferentes idades na região Oeste da Bahia, 2017. 


\begin{tabular}{cccccc}
\hline Áreas & Idades (anos) & -Profundidade- (m) & & & \\
& & $\mathbf{0 - 0 , 1 0}$ & $\mathbf{0 , 1 0 - 0 , 2 0}$ & $\mathbf{0 , 2 0 - 0 , 3 0}$ & $\mathbf{0 , 3 0 - 0 , 4 0}$ \\
\hline CN & - & $\mathbf{9 8 , 0 7 a A}$ & $97,89 a A$ & $\mathbf{9 8 , 5 4 a A}$ & $\mathbf{9 7 , 5 9 a A}$ \\
CAFÉ & $\mathbf{3}$ & $\mathbf{9 4 , 6 6 a A}$ & $\mathbf{9 0 , 0 8 b A B}$ & $\mathbf{8 4 , 6 2 a A}$ & $\mathbf{7 5 , 3 8 b C}$ \\
CAFÉ & $\mathbf{2 0}$ & $\mathbf{9 5 , 2 2 a A}$ & $\mathbf{9 4 , 0 9 a b A}$ & $\mathbf{9 5 , 0 6 a A}$ & $\mathbf{9 1 , 2 4 a A}$ \\
\hline
\end{tabular}

As letras minúsculas indicam as medias na coluna e nas linhas as letras maiúsculas. As médias seguidas pela mesma lesta não diferem estatisticamente entre si pelo teste de Tukeyà $5 \%$ de probabilidade de erro. $\mathrm{CN}=\mathrm{Cerrado}$ nativo.

Em se tratando do estoque de carbono, pode-se observar na Tabela 2 que na camada mais superficial ( 0 a $0,10 \mathrm{~m})$ o cerrado nativo apresentou menor estoque de carbono, comparado às áreas de café em diferentes idades, provavelmente o carbono na área nativa já esteja estabilizado. E as áreas de café não se diferenciaram estatisticamente entre si. Assim como para o $\mathrm{CO}_{2}$ equivalente (Tabela 3), mostrando o mesmo comportamento do estoque de carbono, evidenciando que nas camadas menos profundas (0 a $0,10 \mathrm{~m})$, da área de sistema natural apresentou menores valores para o CO2 equivalente.Essa manutenção da matéria orgânica do solo na camada mais superficial é um ponto bastante positivo em relação à dinâmica do $\mathrm{C}$ no sistema ao longo do tempo e também foi relatada por outros autores (RANGEL; SILVA; GUIMARÃES, 2007; SILVA et al., 2015). Para eles, aliado ao não revolvimento do solo, o cultivo de culturas perenes e o manejo orgânico são de grande importância na preservação da integridade da estrutura do solo e, consequentemente, na manutenção dos estoques de $\mathrm{C}$.

Tabela 2: Estoque de carbono total no solo em áreas cultivadas com café em diferentes idades na região Oeste da Bahia, 2017.

\begin{tabular}{cccccc}
\hline \multicolumn{7}{c}{ Estoque de C } \\
\hline Áreas & Idades (anos) & -Profundidade-(m) & & & \\
& & $\mathbf{0 - 0 , 1 0}$ & $\mathbf{0 , 1 0 - 0 , 2 0}$ & $\mathbf{0 , 2 0 - 0 , 3 0}$ & $\mathbf{0 , 3 0 - 0 , 4 0}$ \\
\hline CN & - & $\mathbf{1 3 , 5 7 b A}$ & $\mathbf{1 4 , 8 1 a A}$ & $\mathbf{1 0 , 9 7 a A}$ & $\mathbf{9 , 3 8 a A}$ \\
CAFÉ & $\mathbf{3}$ & $\mathbf{2 4 , 0 3 a A}$ & $\mathbf{1 6 , 0 9 a B}$ & $\mathbf{8 , 9 0 a C}$ & $\mathbf{6 , 5 4 a C}$ \\
CAFÉ & $\mathbf{2 0}$ & $\mathbf{2 6 , 4 2 a A}$ & $\mathbf{1 2 , 2 8 a B}$ & $\mathbf{1 0 , 2 5 a B}$ & $\mathbf{7 , 4 3 a B}$ \\
\hline & & & & $\mathbf{C V}=\mathbf{2 3 , 1 4 \%}$ \\
\hline
\end{tabular}

As letras minúsculas indicam as medias na coluna e nas linhas as letras maiúsculas. As médias seguidas pela mesma lesta não diferem estatisticamente entre si pelo teste de Tukeyà $5 \%$ de probabilidade de erro. $\mathrm{CN}=\mathrm{Cerrado}$ nativo.

Tabela 3: CO2 equivalente no solo em áreas cultivadas com café em diferentes idades na região Oeste da Bahia, 2017.

\begin{tabular}{cccccc}
\hline \multicolumn{5}{c}{ CO2 equivalente } \\
\hline Áreas & Idades (anos) & -Profundidade-(m) & & & \\
& & $\mathbf{0 - 0 , 1 0}$ & $\mathbf{0 , 1 0 - 0 , 2 0}$ & $\mathbf{0 , 2 0 - 0 , 3 0}$ & $\mathbf{0 , 3 0 - 0 , 4 0}$ \\
\hline CN & - & $\mathbf{4 9 , 8 0 b A}$ & $\mathbf{5 4 , 3 4 a A}$ & $\mathbf{4 0 , 2 5 a A}$ & $\mathbf{3 4 , 4 1 a A}$ \\
CAFÉ & $\mathbf{3}$ & $\mathbf{8 8 , 2 0 a A}$ & $\mathbf{5 9 , 0 7 a B}$ & $\mathbf{3 2 , 6 7 a C}$ & $\mathbf{2 3 , 9 9 a C}$ \\
CAFÉ & $\mathbf{2 0}$ & $\mathbf{9 6 , 9 7 a A}$ & $\mathbf{4 5 , 0 7 a B}$ & $\mathbf{3 7 , 6 1 a B}$ & $\mathbf{2 7 , 2 8 a B}$ \\
\hline \multicolumn{7}{r}{} & & & & $\mathbf{C V}=\mathbf{2 3 , 1 4 \%}$ \\
\hline
\end{tabular}


As letras minúsculas indicam as medias na coluna e nas linhas as letras maiúsculas. As médias seguidas pela mesma lesta não diferem estatisticamente entre si pelo teste de Tukeyà $5 \%$ de probabilidade de erro. $\mathrm{CN}=\mathrm{Cerrado}$ nativo.

\section{Conclusões}

Nas camadas de 0,10-0,20 e 0,20-0,30 m apresentou maior percentual de macroagregados na área de Cerrado nativo.

$\mathrm{O}$ estoque de Carbono e $\mathrm{CO}_{2}$ equivalente com maiores valores na camada superficial foram encontrados na área de café com três e vinte anos.

\section{Referências}

ALMEIDA, A.S.A. et al.Biomass and Carbon stocks of Sofala Bay Mangrove Forests. Faculty of Agronomy and Forestry, 2014.

CERRI, C. E. P. et al. Tropical agriculture and global warming: impacts and mitigation options.

Scientia Agricola, Piracicaba, v. 64, n. 1, p. 83-99, 2007.

COMPANHIA NACIONAL DE ABASTECIMENTO. Acompanhamento da safra brasileira: café safra 2015/2016: segundo levantamento, v. 2. Brasília, DF, 2016. 99 p.

COTTA; M. K. Quantificação de biomassa e geração de certifcado de emissões reduzidas no consorcio seringueira-cacau.Árvore32: 969-978, 2008.

EMPRESA BRASILEIRA DE PESQUISA AGROPECUÁRIA - EMBRAPA. Manual de métodos de análise de solo. 2. ed. Revisada. Rio de Janeiro: Embrapa Solos, 2011 .

NETTO et al. Influência do manejo sobre a estabilidade de agregados em solo de cerrado sob cafeicultura.II Simpósio de Pesquisa dos Cafés do Brasil, 2001.

PANOSSO, A.R. 2011.107f. Tese (Doutorado) - Faculdade de Ciências Agráriase Veterinárias, Universidade Paulista, Jaboticabal, 2011.

RANGEL, O. J. P.; SILVA, C. A.; GUIMARAES, P. T. G. Estoque e frações da matéria orgânica de Latossolo cultivado com cafeeiro em diferentes espaçamentos e plantios. Revista Brasileira de Ciência do Solo, Viçosa, v. 31, n. 6, p. 1341-1353, 2007.

SOARES C.P.B; OLIVEIRA, M. L.R.Equações para estimar a quantidade de carbono na parte aérea de arvores de eucalipto em Viçosa, MG.Árvore 26: 533-53, 2002. 